\title{
Penggunaan Gyclophosphamide Pulse pada Sindrom Nefrotik Resisten Steroid di Bagian Ilmu Kesehatan Anak Rumah Sakit Umum Pusat Dr. Kariadi, Semarang
}

\author{
$M$ Herumuryawan, Gondo Purwadi, Rochmanadji Widajat \\ Bagian Ilmu kesehatan Anak FK UNDIP / RSUP Dr.Kariadi Semarang
}

\begin{abstract}
Latar belakang. Sindrom nefrotik resisten steroid (SNRS) adalah Sindrom Nefrotik (SN) yang gagal mencapai remisi dengan prednison full dose selama 4 minggu. Berdasarkan Konsensus tatalaksana SN Idiopatik UKK Nefrologi IDAI 2005, pengelolaan SNRS menggunakan cyclophosphamide pulse dosis $500 \mathrm{mg} / \mathrm{m}^{2} 1$ bulan sekali ditambah methylprednisolone alternate dose (AD) selama 6 bulan. Dilaporkan pengelolaan SNRS di RSUP Dr. Kariadi Semarang dengan Cyclophosphamide pulse.

Tujuan. Melaporkan pengalaman pengelolaan SNRS menggunakan cyclophosphamide pulse dosis 500 $\mathrm{mg} / \mathrm{m}^{2} 1$ bulan sekali ditambah methylprednisolone alternate dose, selama 6 bulan

Metode. Desain studi retrospektif. Data sekunder diambil dari catatan medik pasien SNRS yang memenuhi kriteria dalam kurun waktu antara tahun 2006 - 2007. Data yang dikumpulkan meliputi umur, jenis kelamin, hasil pengobatan, dan efek samping pengobatan. Analisa statistik secara diskriptif.

Hasil. Pada periode ini dijumpai 11 kasus SNRS, yang terdiri dari 5 laki-laki dan 6 perempuan, umur 2 - 13 tahun (rata-rata 7,5 tahun). Dari 11 kasus, 4 kasus dengan proteinuria tetap positif setelah pengobatan 3 bulan. Remisi dicapai pada 7 kasus (63,6\%) setelah pengobatan 3 bulan pertama. Pencapaian remisi setelah terapi penuh selama 6 bulan sebanyak 6 kasus ( $54,5 \%$ ). Didapatkan efek samping hematuri mikroskopik selama pengobatan pada 1 kasus. Terapi pada seri kasus ini sesuai Konsensus Tata laksana SN Idiopatik UKK Nefrologi IDAI 2005, tetapi berbeda dengan penelitian lain apabila 3 bulan pertama proteinuria persisten, dosis cyclophosphamide pulse dinaikkan $750 \mathrm{mg} / \mathrm{m}^{2} 1$ bulan sekali selama 3 bulan ditambah methylprednisolone dengan dosis sama dengan dosis 3 bulan pertama.

Kesimpulan. Pada penelitian ini sebagian besar kasus SNRS yang dikelola dengan cyclophosphamide pulse di tambah methylprednisolone AD selama 6 bulan dapat mencapai remisi. (Sari Pediatri 2008; 9(5):309-13).
\end{abstract}

Kata kunci: SNRS, cyclophosphamide pulse, methylprednisolone alternate dose

\footnotetext{
Alamat korespondensi

M Herumuryawan, dr., Sp.A.

Bagian IKA FK UNDIP/RSUP.Dr. Kariadi Semarang

Jl Dr. Soetomo no 16-18. Semarang.
} 


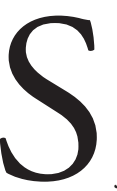
indrom nefrotik resisten steroid (SNRS) adalah sindrom nefrotik yang gagal mencapai remisi dengan terapi prednison dosis penuh full dose $2 \mathrm{mg} / \mathrm{kg} /$ hari selama 4 minggu. ${ }^{1,2,3,4}$ Resisten steroid ada 2 kemungkinan yaitu resisten dini dan resisten lambat. ${ }^{5}$

Terapi SNRS sampai kini masih belum memuaskan. ${ }^{5}$ Dalam penanganannya selain pengobatan medikamentosa juga dibutuhkan pengobatan suportif. Beberapa regimen untuk pengobatan SNRS antara lain cyclophosphamide (CPA) oral dengan prednison $\mathrm{AD}$, cyclosporine (CyA) dengan prednisolone $\mathrm{AD},{ }^{6} \mathrm{CPA}$ pulse dengan prednison $\mathrm{AD},{ }^{7}$ methylprednisolone injeksi dengan prednison oral dan CPA. Obat imunosupresan lain yang dilaporkan telah dipakai adalah vincristine. ${ }^{8}$ Pada SNRS resisten terhadap kortikosteroid, CPA, CyA, dapat diberikan diuretik dikombinasikan dengan ACE inhibitor untuk mengurangi proteinuria. 5,9

Berdasarkan Konsensus Tata laksana SN Idiopatik UKK Nefrologi IDAI 2005, pengelolaan SNRS menggunakan cyclophosphamide pulse dosis $500 \mathrm{mg} /$ $\mathrm{m}^{2} 1$ bulan sekali ditambah methylprednisolone alternate dose $(A D)$, selama 6 bulan atau cyclophosphamide oral dosis $2-3 \mathrm{mg} / \mathrm{kgBB} /$ hari selama 3-6 bulan ditambah methylprednisolone alternate dose $(A D)$ selama 6 bulan kemudian tappering off $1 \mathrm{mg} / \mathrm{kgBB} /$ hari (1 bulan) dilanjutkan dengan $0,5 \mathrm{mg} / \mathrm{kgBB} /$ hari (1 bulan). ${ }^{5}$

Pengobatan CPA pulse dilaporkan memberikan hasil yang lebih baik daripada CPA oral, tetapi jumlah kasus yang dilaporkan hanya sedikit. ${ }^{5}$ Dosis kumulatif pada pemberian CPA pulse lebih kecil daripada CPA oral sehingga efek samping lebih sedikit. Efek samping cyclophosphamide berupa sistisis hemoragis, keluhan saluran cerna, alopesia, sepsis, dan sterilisasi serta kemungkinan keganasan maka penting menentukan pemberian cyclophosphamide secara tepat dan optimal. ${ }^{10}$ Mengingat efek samping, maka dosis kumulatif cyclophosphamide tidak melebihi $200-300 \mathrm{mg} / \mathrm{kgbb} /$ hari. Pemberian cyclophosphamide $500 \mathrm{mg} / \mathrm{m}^{2} / 1$ bulan selama 6 bulan merupakan batas yang cukup aman untuk anak. ${ }^{10,11,12}$

Tujuan penelitian melaporkan pengalaman pengelolaan SNRS menggunakan cyclophosphamide pulse dosis $500 \mathrm{mg} / \mathrm{m}^{2} 1$ bulan sekali ditambah methylprednisolone alternate dose $(A D)$, selama 6 bulan di RSUP Dr. Kariadi Semarang tahun 20062007.

\section{Metode}

Studi bersifat retrospektip, data sekunder diambil dari catatan medik kasus SNRS yang dirawat di Bangsal Nefrologi Bagian Ilmu Kesehatan Anak RSUP Dr.Kariadi/FK Undip Semarang yang memenuhi kriteria dalam kurun waktu antara tahun 2006-2007. Data yang dikumpulkan meliputi umur, jenis kelamin, hasil pengobatan, dan efek samping pengobatan. Analisa statistik secara diskriptif.

\section{Hasil}

Dalam kurun waktu antara tahun 2006 - 2007, didapatkan 11 kasus SNRS yang di rawat di Bangsal Nefrologi Bagian Ilmu Kesehatan Anak RSUP Dr. Kariadi. Semua kasus tersebut telah gagal mencapai remisi dengan prednison full dose selama 4 minggu sehingga didiagnosis sebagai SNRS. Subjek terdiri dari 5 laki-laki dan 6 perempuan $(1: 1,2)$ yang berumur antara 2-13 tahun (rata-rata 7,5 tahun), puncak insiden $>6$ tahun $(64 \%)$ (Tabel 1).

Tabel 1. Distribusi SNRS menurut umur dan jenis kelamin

\begin{tabular}{cccc} 
Umur (tahun) & Laki - laki & Perempuan & Jumlah (\%) \\
\hline $2-4$ & 1 & 1 & $2(18)$ \\
$4-6$ & - & 2 & $2(18)$ \\
$>6$ & 4 & 3 & $7(64)$ \\
\hline Jumlah & 5 & 6 & $11(100)$ \\
\hline
\end{tabular}

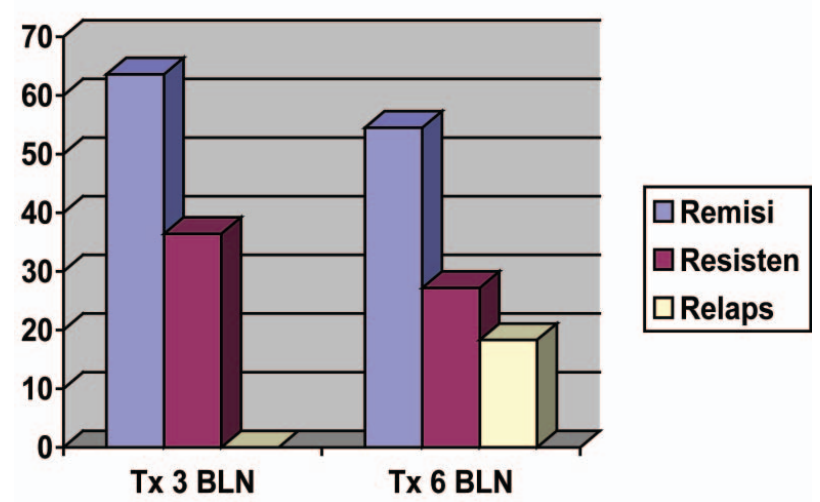

Gambar 1. Hasil pengobatan SNRS dengan CPA 
Sebelas kasus SNRS dengan terapi cyclophosphamide pulse dosis $500 \mathrm{mg} / \mathrm{m}^{2} 1$ bulan sekali ditambah methylprednisolone $A D$ selama 6 bulan. Selama pengobatan 3 bulan pertama dengan CPA didapatkan hasil 4 kasus $(36,4 \%)$ dengan proteinuria tetap positif dan remisi dicapai pada 7 kasus $(63,6 \%)$. Kemudian terapi CPA dilanjutkan 3 bulan berikutnya dengan hasil satu kasus mengalami remisi setelah mendapatkan CPA ke 5.

Dua kasus relaps kemudian terapi diganti dengan golongan diuretik dikombinasi dengan $A C E$ inhibitor. Jadi total selesai pengobatan CPA selama 6 bulan didapatkan hasil jumlah pasien yang mengalami remisi sebanyak 6 kasus (54,5\%), 2 kasus (18,3\%) mengalami relaps, 3 kasus $(27,2 \%)$ resisten (Gambar 1$)$.

Efek samping CPA berupa sistitis hemoragis, keluhan saluran cerna, rambut rontok, infeksi, penekanan sumsum tulang, dan sterilisasi serta kemungkinan keganasan maka penting menentukan pemberian CPA secara tepat dan optimal. Pada penelitian didapatkan 1 kasus dengan hematuri mikroskopik curiga sistitis hemoragis.

\section{Diskusi}

Sekitar $75 \%$ anak Sindrom nefrotik pada usia kurang dari 18 tahun berumur kurang dari 6 tahun pada saat mulainya penyakit tersebut. Sindrom nefrotik kelainan minimal (SNKM) merupakan penyakit primer pada anak pra sekolah dengan puncak insiden umur 3-4 tahun, walaupun penyakit tersebut dapat mulai terjadi pada tiap umur. Diduga bahwa SNKM makin banyak terjadi mulai pada umur kurang dari 5 tahun, kemungkinan lesi ginjalnya berupa SNKM adalah lebih besar dari $90 \%$, sedangkan risiko untuk glomerulo sklerosis fokal segmental (GSFS) dan glomerulo nefritis membrano proliferatif (GNMP) adalah kira-kira 10\%. Kejadian GSFS dan SNRS cenderung meningkat dengan bertambahnya umur. $^{1,2,5}$

Dalam kurun waktu antara tahun 2006-2007, didapatkan 11 kasus SNRS yang dirawat di Bagian Ilmu Kesehatan Anak RSDK, semua kasus tersebut telah gagal mencapai remisi dengan Prednison full dose selama 4 minggu. Semua kasus SNRS ini terdiri dari 5 laki-laki dan 6 perempuan $(1: 1,2)$ yang berumur antara 2-13 tahun (rata-rata 7,5 tahun), puncak insiden $>6$ tahun sebanyak 7 kasus (64\%) (Tabel). Puncak insiden berumur $>6$ tahun hal ini menunjukkan bahwa insiden SNRS sesuai dengan beberapa penelitian bahwa pasien $\mathrm{SN}$ yang resisten steroid merupakan sindrom nefrotik bukan kelainan minimal (SNBKM), dengan bertambahnya umur semakin tinggi angka kejadian GSFS. ${ }^{5}$

Pada seri kasus ini insiden SN antara laki-laki dibanding perempuan adalah $1: 1,2$, hal ini tidak sesuai dengan laporan sebelumnya yang menemukan insiden pada laki-laki lebih tinggi dibanding perempuan. ${ }^{1}$ Gulati dkk (2000) dalam penelitiannya tentang CPA puls sebagai regimen baru pada pengobatan sindrom nefrotik FSGS melaporkan 20 kasus FSGS dengan

Tabel 2. Protokol pengobatan SNRS

\begin{tabular}{|c|c|c|c|c|}
\hline Terapi & $\mathrm{N}$ & Respon $(\%)$ & Efek samping & Keterangan \\
\hline $\begin{array}{l}\text { Methylprednisolonel } \\
\text { triple terapi }\end{array}$ & 32 & 66 & $\begin{array}{l}\text { Infeksi, katarak, growth } \\
\text { retardation, hipertensi }\end{array}$ & Waktu lama (82 minggu) \\
\hline CyA*/Methylprednisolone & 10 & 80 & $\begin{array}{l}\text { Limfoma, nephrotoxicity, } \\
\text { secondary failure }\end{array}$ & $\begin{array}{l}\text { Mahal, lama, } \\
\text { CyA dependent }\end{array}$ \\
\hline CyA + Prednisolone & 20 & 35 & Nephrotoxicity & $\begin{array}{l}\text { Mahal, lama, } \\
C y A \text { dependent }\end{array}$ \\
\hline $\begin{array}{l}\text { CyA oral+Prednisolone AD } \\
\text { (ISKDC) }\end{array}$ & 37 & 27 & $\begin{array}{l}\text { Kejang, perdarahan, } \\
\text { cystitis }\end{array}$ & $\begin{array}{l}\text { Respon jelek, } \\
\text { terapi } 1 \text { thn }\end{array}$ \\
\hline Vincristine & 8 & 25 & Neuropathy perifer & $\begin{array}{l}\text { Respon jelek, } \\
\text { terapi pendek ( } 8 \mathrm{minggu})\end{array}$ \\
\hline IVCP & 20 & 65 & $\begin{array}{l}\text { Alopesia, mual, } \\
\text { muntah }\end{array}$ & $\begin{array}{l}6 \text { bulan terapi, bagus, } \\
\text { ekonomis, respon baik }\end{array}$ \\
\hline
\end{tabular}

${ }^{*}$ CyA: Cyclosporin

Sumber: Gulati S dkk, Indian pediatrics $2000^{7}$

Sari Pediatri, Vol. 9, No. 5, Februari 2008 
perbandingan laki-laki dan perempuan adalah $3: 1$, insiden penyakit dijumpai pada usia 5,5 $\pm 3,5$ tahun. ${ }^{7}$ Gulati dkk (2001) dalam penelitian terapi CPA puls pada sindrom nefrotik relaps sering insiden antara lakilaki dan perempuan adalah $3: 1$, puncak insiden berumur $>7$ tahun. ${ }^{13}$

Terapi SNRS sampai kini masih belum memuaskan. Sebaiknya sebelum pengobatan dimulai dilakukan biopsi ginjal untuk melihat gambaran patologi anatomi, karena gambaran tersebut mempengaruhi prognosis. Dalam penanganannya selain pengobatan medikamentosa juga dibutuhkan pengobatan suportif. ${ }^{5}$

Beberapa protokol pengobatan sindrom nefrotik resisten steroid, sebagai tertera pada Tabel $2 .^{7}$

Pengobatan dengan CPA memberikan hasil lebih baik bila hasil biopsi ginjal menunjukkan SNKM daripada GSFS. Berbagai penelitian telah menunjukkan keunggulan kombinasi cyclophosphamide dengan prednison dibandingkan dengan prednison saja dalam mempertahankan remisi. ${ }^{5,712}$ Pengobatan CPA pulse satu bulan sekali cukup efektif dengan remisi bervariasi antara 25\%-60 \%., ,7,14 Pada laporan seri kasus ini selama pengobatan 3 bulan pertama dengan CPA didapatkan hasil 4 kasus $(36,4 \%)$ proteinuria tetap positif dan remisi dicapai pada 7 kasus $(63,6 \%)$. Kemudian terapi CPA dilanjutkan 3 bulan berikutnya dengan hasil satu kasus mengalami remisi setelah mendapatkan CPA ke 5. Dua kasus relaps kemudian terapi diganti dengan golongan diuretik dikombinasi dengan ACE inhibitor. Jadi setelah selesai pengobatan CPA selama 6 bulan didapatkan hasil jumlah pasien yang mengalami remisi 6 kasus $(54,5 \%), 2$ kasus $(18,3 \%)$ mengalami relaps, 3 kasus $(27,2 \%)$ resisten (Gambar 2).

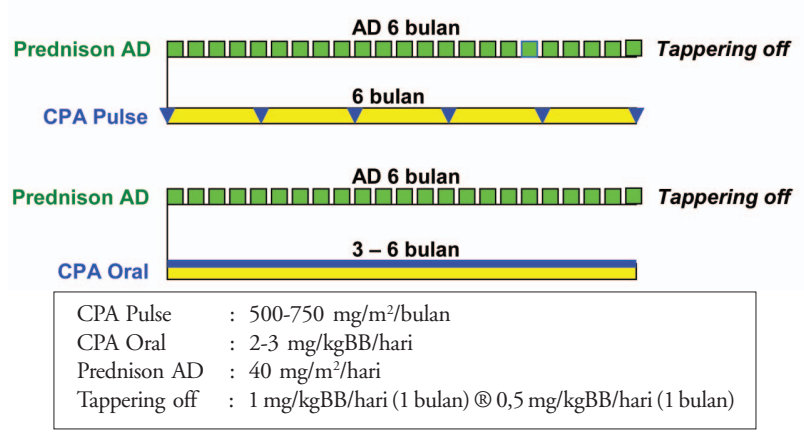

Gambar 2. Protokol pengobatan sindroma nefrotik resisten steroid. Sumber: Alatas H dkk, UKK Nefrologi IDAI $2005^{5}$
Salah satu penelitian mengatakan bahwa apabila dalam 3 bulan pertama pengobatan CPA dosis 500 $\mathrm{mg} / \mathrm{m}^{2}$ pasien proteinuria tetap positip, maka dosis CPA dinaikkan menjadi $750 \mathrm{mg} / \mathrm{m}^{2}$ ditambah prednisolon AD.? Pada seri kasus ini dosis CPA tidak dinaikkan walaupun 4 kasus pada 3 bulan pertama proteinuria tetap positip. Penelitian Gulati dan Kher (2000) pada SNRS yang mendapat pengobatan Intravenous Cyclophosphamide Pulse (IVCP) $500 \mathrm{mg} /$ $\mathrm{m}^{2} 1$ bulan sekali selama 3 bulan ditambah prednisolon $60 \mathrm{mg} / \mathrm{m}^{2} /$ hari selama 4 minggu diikuti $40 \mathrm{mg} / \mathrm{m}^{2} \mathrm{AD}$ selama 4 minggu dan tappering off 4 minggu. Jika selama pengobatan 3 bulan proteinuria persisten, maka dosis IVCP dinaikkan $750 \mathrm{mg} / \mathrm{m}^{2} 1$ bulan sekali selama 3 bulan ditambah prednisolon dengan dosis sama dengan dosis 3 bulan pertama. Dengan skema pengobatan tersebut $65 \%$ pasien mengalami remisi komplit.?

Pemberian cyclophosphamide selain sebagai salah satu pilihan terapi pada SNRS juga untuk mengurangi efek samping pemberian kortikosteroid dosis tinggi, dan memberikan remisi yang lebih panjang. Pada saat terapi dipantau efek samping pengobatan. Cyclophosphamide dihentikan bila terjadi penurunan jumlah leukosit kurang dari $4000 / \mathrm{mmk}$ dan dimulai lagi setelah kembali normal. $4,5,10$

Pengobatan CPA pulse dilaporkan memberikan hasil yang lebih baik daripada CPA oral, tetapi jumlah kasus yang dilaporkan hanya sedikit. Dosis kumulatif pada pemberian CPA pulse lebih kecil daripada CPA oral sehingga efek samping lebih sedikit. Efek samping cyclophosphamide berupa sistisis hemoragis, keluhan saluran cerna, alopesia, sepsis, dan sterilisasi serta kemungkinan keganasan maka penting menentukan pemberian cyclophosphamide secara tepat dan optimal. ${ }^{5}$ Oleh karena efek samping tersebut maka dosis kumulatif cyclophosphamide tidak melebihi 200-300 $\mathrm{mg} / \mathrm{kgbb} / \mathrm{hari}$. Pemberian cyclophosphamide $500 \mathrm{mg} /$ $\mathrm{m}^{2} / 1$ bulan selama 6 bulan merupakan batas yang cukup aman untuk anak-anak. ${ }^{5,7}$

Pada laporan seri kasus ini didapatkan efek samping berupa hematuri mikroskopik dicurigai sebagai sistitis hemoragis sebanyak satu kasus dan setelah pasien di anjurkan untuk minum banyak dan terus menerus baik sebelum pengobatan maupun sesudah pengobatan efek samping tersebut sudah tidak didapatkan lagi. Pada seri kasus ini tidak dilakukan pemeriksaan efek samping infertilitas. 


\section{Kesimpulan}

Pengelolaan SNRS dengan regimen cyclophosphamide pulse di tambah methylprednisolone $\mathrm{AD}$ selama 3 bulan pertama pengobatan remisi dicapai pada 7 kasus $(63,6 \%), 4$ kasus $(36,4 \%)$ proteinuria tetap positif. Terapi CPA dilanjutkan 3 bulan berikutnya dengan hasil 1 kasus remisi setelah CPA ke 5, dua kasus relaps. Setelah selesai pengobatan CPA 6 bulan penuh remisi 6 kasus $(54,5 \%), 2$ kasus $(18,3 \%)$ relaps, 3 kasus $(27,2 \%)$ resisten.

\section{Daftar Pustaka}

1. Kosnadi L. Sindrom nefrotik responsif steroid. Dalam: Kosnadi L, Tatty Ermin S, Rochmanadji Widajat (penyunting). Penyakit ginjal anak. Semarang: BP UNDIP; 2007. h. 105-23.

2. Alatas H, Tambunan T, Trihono PP, Pardede SO. Konsensus tatalaksana SN idiopati pada anak. Dalam: PIT Batam: UKK Nefrologi IDAI 2004:1-14.

3. Hodson EM. Pathology and management of idiopathic nephropatic syndrome in children. Dalam: Proceedings book. Bali: $12^{\text {th }}$ National Congress of Child Health 2002: 57-63.

4. Bagga A, Mantan M. Nephrotic syndrome in children. Indian J Med Res 2005; 122:13-28.

5. Alatas H, Tambunan T, Trihono P, Pardede O. Konsensus tata laksana sindrom nefrotik idiopatik pada anak. Unit kerja koordinasi Nefrologi Ikatan Dokter Anak Indonesia, 2005.

6. Melissa J, William E, David B, Rudolph P. Long-term cyclosporine therapy for pediatric nephrotic syndrome. Indian pediatr 2006; 43:14-9.

7. Gulati S, Kher V. Intravenous pulse cyclophosphamide a new regime for steroid resistant focal segmental glomerulosclerosis. Indian pediatr 2000; 37:141-8.

8. Kausman JY, Yin L, Jones CL, Johnstone L, Powell HR. Vincristine treatment in steroid-dependent nephrotic syndrome. Pediatr Nephrol 2005; 20:1416-9.

9. Delucchi A, Cano F, Rodriguez E. Enalapril effective in steroid-resistant nephrotic syndrome. Pediatr Nephrol 2000; 14:1088-91.

10. Noer MS. SN Resisten steroid dan permasalahannya. Dalam: SINAS Nefrologi anak IX Malang: IDAI 2003: 16-36.

11. Gulati S, Debashish S, Raj K. Sharma, Ajay Sharma. Steroid resistant nephrotic syndrome: role of histopathology. Indian Pediatr 2006; 43:55-60.

12. Kevin D, David B, William E. Pediatric steroid-resistant nephrotic syndrome. Curr Probl Pediatr 2001:280-307.

13. Gulati S, Raj K. Sharma, Kher V. Pulse cyclophosphamide therapy in frequently relapsing nephrotic syndrome. Nephrol Dial Transplant 2001; 16:2013-7.

14. Bajpai A, Bagga A, Hari P, Dinda A, Srivastava RN. Intravenous cyclophosphamide in steroid resistant nephrotic syndrome. Pediatr Nephrol 2003; 18:351-6. 